\title{
SPECIAL COMMITTEE ON CONFIDENTIALITY AND MEDICAL INFORMATION SYSTEMS
}

At a meeting of Council on 16 June 1976 it was agreed to set up a small Special Committee to (a) act as an authoritative group of people to answer queries; (b) to consider requests or complaints in relation to data collection systems.

The Committee was constituted as follows: Professor Sir Martin Roth (Chairman); Professor J. K. Wing (Secretary); Dr A. Adelstein; Dr J. Baldwin; Mr J. Barter (NAMH); Dr A. V. Campbell; Dr D. H. Clark; Mr P. Gorbach; Dr M. A. Heasman; Dr A. Isaacs; $\mathrm{Dr} \mathrm{M}$. Markowe; $\mathrm{Mr} \mathrm{P}$. Oakley; $\mathrm{Mr} \mathrm{R}$. Stevenson; and its recommendations were approved by Council on 14 March 1979.

\section{Recommendations}

1. Types of Psychiatric Case Registers

The Special Committee has considered the problems of confidentiality raised by case registers with computer data linkage facilities which hold information about identifiable individuals. Two main types of medical case registers have been discussed, and our recommendations are concerned chiefly with these.

Relatively small registers under local medical control, used mainly for clinical and research purposes: The essence of this type of register is not so much its size as the extent to which it is under control by local professional people who supply information, with adequate representation of the interests of patients. (See section 2.) Most small registers do not enter the names of patients on the computer file and only enter addresses in coded form.

Large regional and national systems, used mainly for descriptive statistics as well as research: The main system under consideration is the Mental Health Enquiry, forms for which are collected regionally and filed centrally. A major problem is that medical control of the information collected at the MHE is too remote for supervision by those who supply the data, and the extent that the system is operated by a Government department gives rise to doubts about the uses to which the data may be put. (See Section 3.)

There is another category of registers not regarded as within the remit of the Special Committee. (See Section 4.)

\section{Local Registers Control}

There should be a named medical officer responsible for all issues concerning confidentiality. This officer should be licensed by an Ethical Committee composed of representatives of the professional people who supply information to the register and with a representative (e.g. from the local Community Health Council) specifically concerned with the interests of patients, and a representative of the register staff (e.g. the medical officer responsible for security). There should be provision for substitutes so that someone representing patients and someone from the register will usually be present. The Committee should be set up by the local hospital Ethical Committee and could be identical with it. The College's Special Committee on Confidentiality and Medical Information Systems is prepared to deal with problems referred by local ethical committees or by individual members of the College.

Code of practice

The Ethical Committee should approve and supervise a code of practice ${ }^{*}$ governing the rules of access to confidential information held in the register, the type of identifying and other data held on computer file, and security precautions (both physical-i.e. access to the register premises and files-and concerned with computer operations). All personnel with access to confidential records should be thoroughly briefed in the code of practice and be aware that they are likely to be dismissed if they breach the code. The effect of these precautions is to prevent confidential data being seen by any unauthorized person or being used for any illegitimate purpose.

\section{Contact with patients}

The consent of the patient's doctort (or an appointed medical representative) should always be obtained before making contact with any patient. The patient must be given the opportunity to refuse contact. Relatives should never be approached except with the patient's permission. (These rules govern all research projects, whether or not they are based on register samples.)

\section{Consent from patients}

It would be impossible in practice to obtain consent

\footnotetext{
"We recommend the adoption of a detailed code of practice such as the one suggested by Baldwin, Leff and Wing (1976), or the virtually identical code recommended by the Privacy Committee of the Scottish Health Services Planning Council.

†The patient's doctor may be the responsible consultant psychiatrist or, particularly in the case of follow-up studies carried out after the patient has ceased contact with the hospital, the general practitioner.
} 
from patients (e.g. at the time of admission to hospital) since the explanation would have to be given by a nurse or doctor not concerned with the register or familiar with the details of its operation and very busy with other work. Only a minority of patients would in fact be asked, and it is doubtful how far their decision (whether they agreed or refused) could be said to be well-informed. It is impracticable to employ special register staff for this task.

We recommend, therefore, that in addition to any paragraph in the patients' information booklet pointing out that medical records are kept mainly for the patient's benefit a paragraph along the following lines also be included:

'For the purposes of your present and future medical treatment some details of your condition and care will be recorded.) Some of this information may be held, under medical control, on a computer for purposes of research and to indicate the kind of health services that are required. Great care is taken at all times to ensure that high standards of confidentiality are maintained.'

Provision should be made for any questions on this paragraph to be answered by someone familiar with the particular system involved.

\section{Access by patients to information stored on registers}

The problem of access by patients to the file held by the register cannot be separated from the general question of access to medical records. Since the data held on the register are very restricted and contain no information not in the records, it is suggested that it is not necessary to make extra rules. If a patient were granted access to his or her medical records there would be no problem in making the register file available as well. The only sensitive item is likely to be diagnosis. Register directors should not make information available to patients unless the clinician responsible has agreed.

\section{Sanctions}

The code of practice suggested by Baldwin, Leff and Wing (1976) recommends that register staff who neglect any duty in respect of confidentiality should be dismissed. Such a clause should be included in the contract of employment.

It is recommended that any contravention of the code of practice (particularly to the extent of making confidential information available to agencies which could use it to the detriment of the patient e.g. to the police, to commercial organisations, etc.) should be made a criminal offence. We do not believe that any such transfer, which would be in blatant disregard of the rules of practice, could be regarded as wellintentioned, or that good intentions should constitute a defence against criminal charges.

\section{National and Regional Registers}

The recommendations listed in Section 2 also apply to national and regional registers.

It is further recommended that responsibility for the Mental Health Enquiry should be devolved to a non-Governmental body, as is already the case in Scotland. Nominees from Government should not be in a majority on the controlling committee and there should be an independent chairman.

\section{Other Registers}

The purpose of other types of register, such as those set up by non-medical agencies but which contain medical information (e.g. child abuse registers held by local authorities) are so totally different from those of registers considered in Sections 2 and 3 that the Special Committee did not feel that they lay within its remit. Research registers are precluded, by the code of practice recommended, from passing information about identifiable persons to any other agency, except for specified, restricted and approved research, and then only with the permission of the doctor supplying the information to the register.

\section{ASSISTANT EDITORS}

The British Journal of Psychiatry is looking for additional assistant editors. If you are interested in writing, or in preparing papers for the press, or in the other aspects of producing the Journal, the Bulletin, and occasional books, please write or telephone the Editor at 17 Belgrave Square, SWIX 8PG (telephone: 01-235 8857) for further information. 